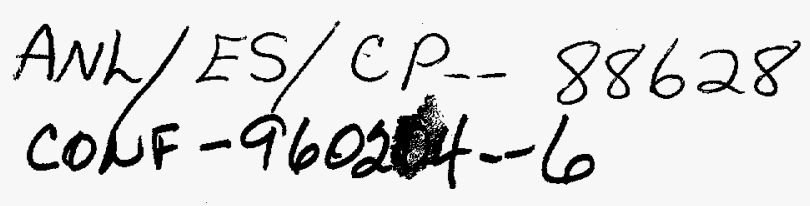

\title{
The 1995 HEV Challenge: Results and Technology Summary
}

\author{
Nicole LeBlanc, Robert Larsen, and Michael Duoba \\ Argonne National Laboratory
}

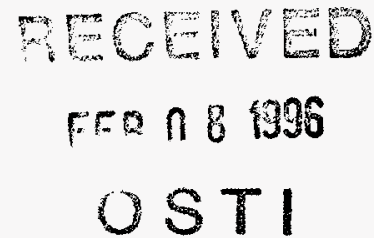

\section{ABSTRACT}

The objective of this paper is to analyze and summarize the performance results and the technology used in the 1995 Hybrid Electric Vehicle (HEV) Challenge. Government and industry are exploring hybrid electric vehicle technology to significantly improve fuel economy and reduce emissions of the vehicles without sacrificing performance. This last in a three-year series of HEV competitions provided the testing grounds to evaluate the different approaches of 29 universities and colleges constructing HEVs. These HEVs competed in an array of events, including: acceleration, emissions testing, consumer acceptance, range, vehicle handling, HVAC testing, fuel economy, and engineering design. The teams also documented the attributes of their vehicles in the technical reports. The strategies and approaches to HEV design are analyzed on the basis of the data from each of the events. The overall performance for promising HEV approaches is also examined. Additional significant design approaches employed by the teams are presented, and the results from the events are discussed.

\section{INTRODUCTION}

The 1995 HEV Challenge was the final hybrid electric vehicle competition in a three-year series. Co-sponsored by the U.S. Department of Energy, the Chrysler Corp., and Natural Resources - Canada, the 1995 HEV Challenge determined the best overall performing HEV in each of three distinct classes. As a result of innovative and advanced designs, the HEV Challenge provided a wealth of technical data that complement and enhance industry's and government's research and development efforts. Collegiate teams had to develop innovative and environmentally responsible vehicles that combine electric and thermal power to improve mileage and reduce emissions and yet perform like conventional vehicles.

The classes were the Ford Escort Class, the Saturn Sedan Class, and the Chrysler Neon Class (new for 1995). Each class was evaluated independently of the other, and each class had distinct design criteria specified by the competition organizers (see Appendix A, Table 6. for a summary of the vehicle specifications).

Ford Escort Class - These hybrids, based on the 1992 Ford Escort Wagon, had significant electric-only range. These vehicles were required to have a minimum electric-only range of $40 \mathrm{~km}$ at a speed of $48 \mathrm{~km} / \mathrm{h}$. The HEV range required a minimum of $482 \mathrm{~km}$ at $72 \mathrm{~km} / \mathrm{h}$. The teams were limited to reformulated gasoline (Phase I), methanol ( $85 \%$ ), and ethanol $(95 \%)$. The weight of the vehicles was limited to the gross vehicle weight plus $15 \%$.

Saturn Sedan Class - These hybrids were charge-sustaining hybrids with minimal electric-only range and were based on 1991 SL2 Saturn Sedans. These vehicles could not be charged from the grid. The vehicles were required to have a minimum electric-only range of $8 \mathrm{~km}$ at $48 \mathrm{~km} / \mathrm{h}$ and a minimum HEV range of $482 \mathrm{~km}$ at $72 \mathrm{~km} / \mathrm{h}$. The vehicles used methanol ( $85 \%)$ or ethanol (95\%) for liquid fuel. Vehicle weight was limited to the gross vehicle weight plus $15 \%$.

Chrysler Neon Class - The Neons converted to HEVs in this class were not limited to a specific hybrid design. The required ranges for the Neon class were $8 \mathrm{~km}$ at $48 \mathrm{~km} / \mathrm{h}$ for electric and $241 \mathrm{~km}$ at $89 \mathrm{~km} / \mathrm{h}$ under hybrid power. The vehicles were limited to compressed natural gas and had to remain under the gross vehicle weight. The vehicles were allowed to charge from the charging station. This class was the only class required to have an operating heating ventilation and air-conditioning (HVAC) system. 


\section{DISCLAMMIER}

Portions of this document may be illegible in electronic image products. Images are produced from the best available original document. 
The HEV Challenge consisted of events in which vehicle designs and overall dynamic performance were evaluated. The events included Acceleration, Handling, Range, Emissions, Fuel Economy, Consumer Acceptability, Engineering Design Review, and Technical Reports [1]. This paper presents the results of this competition and analyzes the best vehicle designs.

\section{HEV CHALLENGE EVENTS}

\section{ACCELERATION AND HANDLING EVENTS}

The performance events, such as the Acceleration and Handling Events, are designed to test vehicle power, maneuverability, and handling. The Acceleration Event involved a hard acceleration over a 201-m straight-away. The Handling Event involved an obstacle course that includes a slalom, figure eight, quick accelerations, park and reverse, and a driver change over a $96.5 \mathrm{~m}$ distance (see Attachment B, Figure 5). Timing lights were used in both events to signal the start and end of the run. The operation mode of the vehicle was specified only in the Acceleration Event. All classes had to make at least one run in the hybrid mode, and the Escort Class had to make an additional run in electric-only mode.

The top speeds of the vehicles during the acceleration run are listed in Table 1. Of the top five parallel and series vehicles, the parallel vehicle demonstrated higher speeds by $13.2 \%$ over the series. The average acceleration times show the parallel hybrids outperforming the series hybrids by $2.38 \mathrm{~s}$.

\begin{tabular}{|c|c|c|c|c|c|}
\hline Parallel & $\begin{array}{c}\text { Time } \\
\text { (s) }\end{array}$ & $\begin{array}{l}\text { Top } \\
\text { Speed } \\
(\mathrm{km} / \mathrm{h})\end{array}$ & Series & $\begin{array}{c}\text { Time } \\
\text { (s) }\end{array}$ & $\begin{array}{l}\text { Top } \\
\text { Speed } \\
(\mathrm{km} / \mathrm{h})\end{array}$ \\
\hline ETS & $\overline{10.75}$ & 95 & CSU, Chico & 10.34 & 100 \\
\hline Texas Tech & 11.10 & 93 & VA Tech & 13.04 & 71 \\
\hline WWU & 11.23 & 85 & Navy & 14.03 & 71 \\
\hline Wayne St. & 11.41 & 87 & U. of WI & 14.19 & 72 \\
\hline U. of Alberta & 11.71 & 87 & Penn St. & 14.55 & 74 \\
\hline Average & 11.24 & 89.4 & Average & 13.21 & 77.6 \\
\hline
\end{tabular}

The results of the Handling Event paralleled those of the Acceleration Event, with the series vehicles performing, on average, slower than the parallel hybrids by $1.32 \mathrm{~s}$. The Handling Event was greatly influenced by the driver's skill in comparison with the Acceleration Event. The times between the two classes were much closer; the averages differed by only by $1.2 \%$ (see Table 2). The fastest hybrid was the University of Wisconsin's vehicle, which was a series hybrid.

Table 2. Handling Times of the Five Top-Performing
Parallel and Series Vehicles
\begin{tabular}{|l|c|l|c|}
\hline Parallel & Times (sec) & Series & Times (sec) \\
\hline Texas Tech & 106.18 & U. of WI & 100.56 \\
U. of Tenn. & 107.94 & Penn State & 109.25 \\
Wayne St. & 108.41 & CSU, Chico & 112.69 \\
CSU, Fresno & 110.48 & WVU & 113.35 \\
U. of Alberta & 112.60 & U. of FL & 116.34 \\
\hline Average & 109.12 & Average & 110.44 \\
\hline
\end{tabular}

\section{RANGE EVENT}

The Range Event was designed to demonstrate vehicle reliability and range potential on a $2.89-\mathrm{km}$ closed track (see Attachment B, Figure 6). The vehicles were given a limited amount of gasoline-equivalent fuel $(11 \mathrm{~L}$ for the Neons and Escorts and $12 \mathrm{~L}$ for the Saturns), a maximum time, and minimum average lap speeds. Only one to two vehicles were expected to still be on the track at the end of the event. Only one class was allowed on the track at a time (a maximum of 12 vehicles). The teams were able to choose the optimal starting state of charge (SOC) in their battery packs on the basis of their driving strategy. The average lap speeds were limited to a minimum of $64.4 \mathrm{~km} / \mathrm{h}$ and a maximum of 88.5 $\mathrm{km} / \mathrm{h}$ on the basis of prudent speed limitations of the track.

Because the objective of the Range Event was to have the vehicles "run-till-they-drop," the amount of fuel for each class had to be calculated. The liquid fuel limits were based on previous HEV Challenge results and hybrid types. As an example, estimations were based on a maximum of $3.5 \mathrm{~h}$ of track time for the Escort Class at an average lap speed of 67.5 $\mathrm{km} / \mathrm{h}$. From the total distance estimated $(236.5 \mathrm{~km})$, a spreadsheet calculated fuel economy on the basis of possible combinations of electric and hybrid ranges. Thus, the Range Event for the Escort Class included $3.5 \mathrm{~h}$ of track time with only $11 \mathrm{~L}$ of liquid fuel, a volume based on estimations that vehicles would not achieve greater than $20.1 \mathrm{~km} / \mathrm{L}$ in hybrid mode (see Table 3).

\begin{tabular}{|l|c|c|c|}
\hline \multicolumn{3}{|l|}{ Table 3. Range Event } & \multicolumn{1}{c|}{} \\
\hline Class & Time (h) & Fuel (L) & Est. Fuel Economy* \\
\hline Escort Class & 3.5 & 11 & $20.1 \mathrm{~km} / \mathrm{L}$ \\
Saturn Class & 3.0 & 12 & $15.6 \mathrm{~km} / \mathrm{L}$ \\
Neon Class & 3.0 & 11 & $17.0 \mathrm{~km} / \mathrm{L}$ \\
\hline
\end{tabular}

* Fuel Economy calculations based only on the estimated HEV miles. Estimates do not include the electric-only miles, which would reflect a higher fuel economy.

Only one vehicle from each class was left on the track at the end of the Range event. The teams with vehicles on the track were the University of Alberta (Escort), Western Washington University (Neon), and California State University, Fresno (Saturn). Because of the structure of this event, the remaining liquid fuel on board was not measured. 


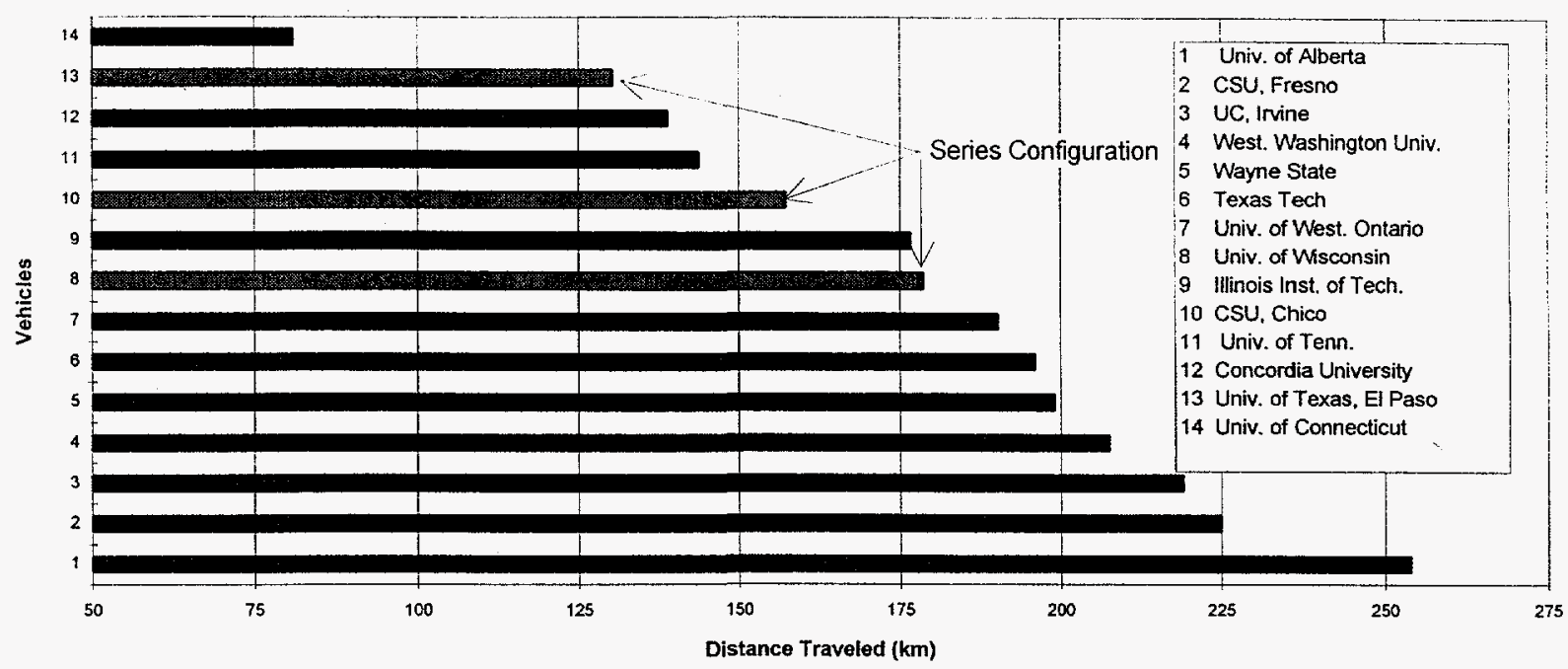

Figure 1. Range Event Results of Vehicles Completing More Than $50 \mathrm{~km}$.

Reliable Vehicle Designs - The Range Event also identified vehicles with reliability problems. Only eight vehicles traveled over $160.9 \mathrm{~km}$. Four of the Escort Class vehicles ran for over $160.9 \mathrm{~km}$, although it was expected that most, if not all, of the vehicles would run until they were out of fuel and not break down. The Saturn and Neon Classes both had two vehicles that ran for more than $160.9 \mathrm{~km}$ (see Figure 1).

The robustness of the parallel hybrids is best seen in this event. There was only one series vehicle, that was built by the University of Wisconsin, that completed over $160.9 \mathrm{~km}$, and it traveled the shortest distance of the Escort vehicles. The vehicles that were out last on the track in the Saturn and Neon Classes were both parallel configurations.

\section{ENERGY ECONOMY}

Energy economy was measured during the Emissions Event. The city cycle of the Federal Test Procedure was used as the basis for calculating fuel economy. The raw data were adjusted for state of charge (SOC) corrections and displayed in gasoline-equivalent values. These results are analyzed in detail in "Hybrid Electric Vehicle Dynamometer Testing with State-of-Charge Corrections of 1995 HEV Challenge Vehicles," SAE paper 96P-176 by Michael Duoba et al.

Most of the second- and third-year vehicles were tested in the Energy Economy Event. The Neon Class suffered from firstyear reliability problems, resulting in the fewest number of vehicles tested from any class. Data were collected from 7 out of the 8 Escorts, 7 out of 10 Saturns, and only 3 out of 11 Neons. By mistake, the Escorts and Saturns were tested at dynamometer inertia settings of $113 \mathrm{~kg}-136 \mathrm{~kg}$ above their actual weight.

\begin{tabular}{|l|c|c|c|}
\hline \multicolumn{3}{|c|}{ Table 4. Best Fuel Economy Performances } & Pel Weight \\
\hline School & Class & $\begin{array}{c}\text { Fuel Economy } \\
(\mathbf{k m} / \mathbf{L})^{*}\end{array}$ & $\begin{array}{c}\text { Vehicle Weing } \\
\text { (kg) }\end{array}$ \\
\hline ETS & Saturn & 18.1 & 1447.4 \\
\hline CSU, Chico & Saturn & 13.8 & 1709.4 \\
\hline CSU, Fresno & Saturn & 11.6 & 1438.8 \\
\hline '91 Saturn SL2 & Stock & 12.3 & 1040.4 \\
\hline Wayne State & Escort & 11.4 & 1800.0 \\
\hline U. of Alberta & Escort & 11.1 & 1617.3 \\
\hline U.C., Irvine & Escort & 10.9 & 1675.8 \\
\hline '92 Ford Escort & Stock & 14.0 & 1090.2 \\
\hline Texas Tech & Neon & 10.2 & 1575.6 \\
\hline Univ. of Tenn & Neon & 9.9 & 1496.0 \\
\hline W.W.U. & Neon & 9.3 & 1576.5 \\
\hline '95 Chrysl. Neon & Stock & 12.3 & 1057.6 \\
\hline
\end{tabular}

* SOC-corrected in gasoline equivalent kilometers per liter.

Although two of the three classes were tested at artificially high inertia weights on the dynamometer rolls, fuel economy was still lower than that of comparable gasoline equivalentvehicles. Only in the case of ETS and CSU, Chico (both Saturn Class), did hybrids demonstrate higher fuel economy than the stock vehicle. There was no correlation between vehicle weight and fuel economy. There was no operator control over such factors as hybrid-control strategy and configuration that could affect fuel economy. No comparisons are made between parallel and series hybrids because of the lack of data from series hybrids from this event.

Energy economy in electric-only mode was collected on the test track at the Chrysler Technology Center. Each class had to demonstrate minimum electric-only ranges: $40 \mathrm{~km}$ at 48 $\mathrm{km} / \mathrm{h}$ for the Escort Class and $8 \mathrm{~km}$ at $48 \mathrm{~km} / \mathrm{h}$ for the Saturn and Neon Classes. The results from the Escort Class are shown in Figure 2 by configuration. The Saturn and Neon Classes are shown together in Figure 3, because both classes were required to go the same minimum distance. 
Escort Class: Total Kilowatt-Hours Consumption from the ZEV Verification

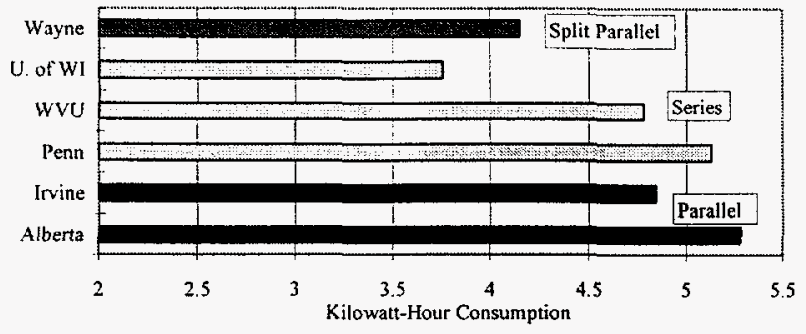

Figure 2. Total Kilowatt-Hour Consumption from the ZEV Verification for the Escort Class over a 40 $\mathrm{km}$ Distance.

Saturn \& Neon: Total Kilowatt-Hour Consumption from the ZEV Verification

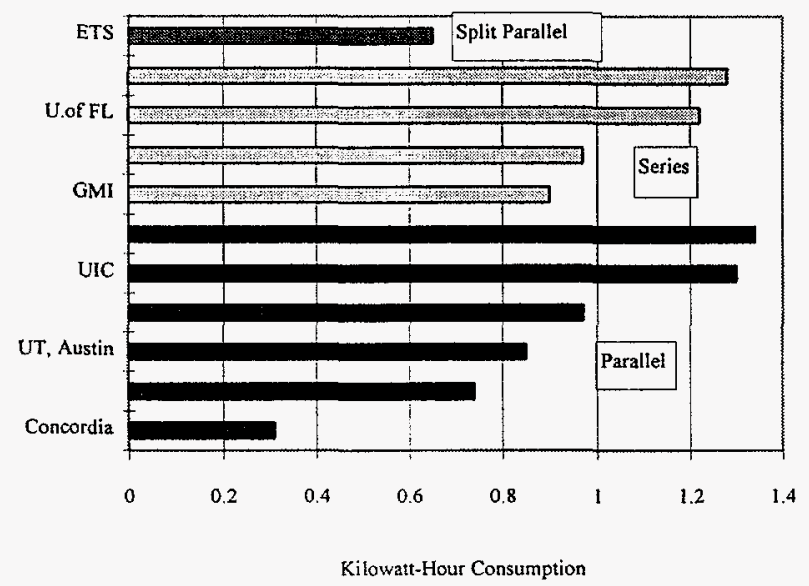

Figure 3. Total Kilowatt-Hour Consumption from the ZEV Verification for the Saturn and Neon Classes over a $8 \mathrm{~km}$ Distance.

The difference between the average kilowatt-hour consumption for the parallel and series configurations is small for both the Escorts (Figure 2) and the Saturns/Neons (Figure 3). The average kilowatt-hour consumptions for the parallel and series Escorts are $5.06 \mathrm{kWh}$ and $4.56 \mathrm{kWh}$, respectively. Because of the few data points for the Escort Class, no conclusions can be drawn from the efficiency differences between parallel and series configurations. There was also no correlation between vehicle weight and energy consumption for the Escorts.

For the Saturns and Neons, the parallel and series average kilowatt-hour consumptions were $0.92 \mathrm{kWh}$ and $1.09 \mathrm{kWh}$, respectively. The correlation between a heavier vehicle and greater energy consumption is seen in Figure 4 by using the "corner test of association" developed by Olmstead and Tukey [2]. The series hybrids were heavier overall than the parallel hybrids. Why did the series hybrids have a lower energy economy? Could it be a result of the additional weight from a larger battery capacity? Looking at the relationship between the battery pack weight to total vehicle weight and the energy consumption, there was no direct correlation. Because of the few data points available, drawing any conclusions about the effect of hybrid configuration efficiency is difficult. The losses associated with the onboard generation of electricity and the in/out losses of the battery pack are other factors that could help explain the differences in efficiency. However, a common factor of the higher efficiency vehicles was their lower overall vehicle weight. For every $100-\mathrm{kg}$ increase in weight, energy consumption increased by $0.37 \mathrm{kWh}$ at an average constant lap speed of $48 \mathrm{~km} / \mathrm{h}$. Noted that the vehicle weights reflected in the figure below consist of fully loaded vehicles (fuel and passengers).

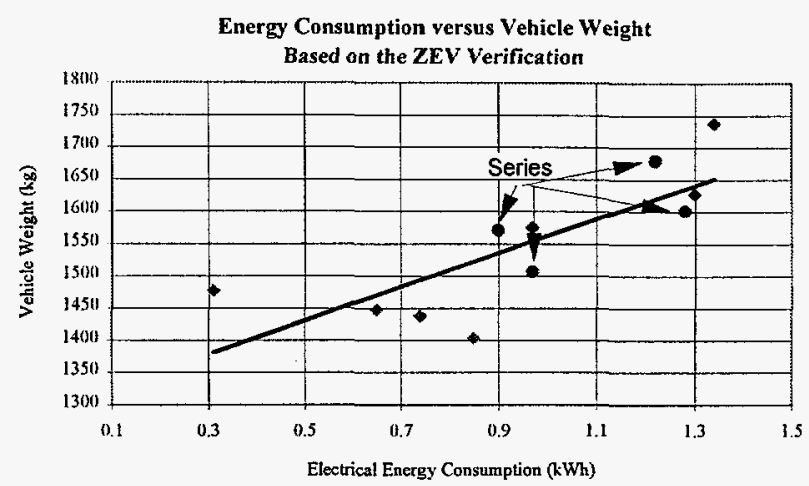

Figure 4. Energy Consumption versus Vehicle Weight Based on ZEV Range Verification for Series and Parallel HEVs.

\section{EMISSIONS EVENT}

The best emissions results of each vehicle in each class are presented in Table 5. Although a few of the teams demonstrated good simultaneous control of pollutants, even as low as California's ULEV requirements, the remaining hybrids showed room for improvement. As shown by the median emission results of each class in Table 6, the Saturn Class had one of the largest variation in results. The spread in the emissions results from this class could be linked to the initial HEV Challenge requirements. This class was required to remove the original engine and drivetrain of the vehicle when the teams first received it. The use of non-OEM engines made tuning the engine for low emissions difficult, especially with the use of alcohol fuels.

California State University (CSU), Fresno team indicated that its emissions results were affected by the control strategy. CSU, Fresno had a parallel hybrid that incorporated the electric motor for load-leveling the engine (a Suzuki 1.3-L engine running on ethanol). The control strategy was not fully operational at the competition. To meet the passive control system requirements, the electric motor was set at an average operating range on the basis of previous testing. The operation of the electric motor was implemented through the position on the accelerator pedal. This set up left the engine operating at full open throttle during the trace where the electric motor should have been off-setting the load requirements on the engine [3]. 
Problems with developing a sufficiently sophisticated control strategy to realize the potential energy economy and emissions gains possible with HEVs, such as shown by CSU, Fresno, illustrate of the some of the difficulties the teams encountered. In addition, reliability issues attributed to prototype vehicles also plagued the schools. GMI reported electrical problems, and UTEP experienced a small electrical fire while running the HVAC testing. The Escort Class, third-year competitors, had the fewest mechanical/electrical problems overall. Seven out of the eight vehicles completed the emissions testing with no major failures.

Only three Neon vehicles finished emissions testing. Although this class had its share of control strategies that were not fully operational and vehicle breakdowns, the University of Tennessee was able to obtain ULEV emission control. The vehicle was a parallel hybrid that used a $1.0-\mathrm{L}$ Geo engine converted to run on natural gas. This vehicle demonstrated that low-emission results could be obtained with a reliable, fully functioning control system.

\begin{tabular}{|l|l|c|c|c|}
\hline \multicolumn{4}{|l|}{ Table 5. Best Emissions Performances } & \\
\hline School & Class & $\begin{array}{c}\text { NMHC } \\
(\mathbf{g} / \mathbf{m i})\end{array}$ & $\begin{array}{c}\text { CO } \\
(\mathrm{g} / \mathrm{mi})\end{array}$ & $\begin{array}{c}\mathrm{NO}_{\mathbf{X}} \\
(\mathrm{g} / \mathrm{mi})\end{array}$ \\
\hline Wayne St. & Escort & 0.040 & 0.540 & 0.090 \\
\hline CSU, Fresno & Saturn & 0.293 & 5.074 & 0.312 \\
\hline IIT & Saturn & 0.245 & 3.874 & 1.497 \\
\hline U. of Tenn. & Neon & 0.019 & 0.504 & 0.050 \\
\hline
\end{tabular}

\begin{tabular}{|l|c|c|c|}
\hline Table 6. The Median of Each Class Emissions Results. \\
\hline School & $\begin{array}{c}\text { NMHC } \\
(\mathrm{g} / \mathrm{mi})\end{array}$ & $\begin{array}{c}\text { CO } \\
(\mathrm{g} / \mathrm{mi})\end{array}$ & $\begin{array}{c}\text { NO } \\
(\mathrm{g} / \mathrm{mi})\end{array}$ \\
\hline Ford Class & 0.211 & 6.901 & 0.708 \\
\hline Saturn Class & 0.422 & 19.287 & 1.286 \\
\hline Neon Class & 0.010 & 0.240 & 0.831 \\
\hline
\end{tabular}

\section{CONSUMER ACCEPTABILITY}

The Consumer Acceptability Event was added for the 1995 HEV Challenge as a result input from the teams and Chrysler. In most cases, these prototype vehicles have had only a few hundred miles of development on them, with only one or two drivers. This event was developed to qualitatively evaluate a prospective buyer's acceptability of the finished HEV conversions. There was a static and dynamic portion of the event. The judges for the static portion evaluated the following:

- Comfort/roominess;

- Usable interior storage;

- Instrument panel and cluster;

- Controls;

- Cargo space;

- Customer maintenance labels; and

- Miscellaneous items, such as the audio system, alarms, and interior lighting.

The dynamic portion of this event involved one judge, a professional driver, driving all of the vehicles in one class. The score sheet used to evaluate the vehicles is shown in
Attachment C. It covered such items as handling, directional stability, maneuvering and parking, brake feel and effectiveness, road noise, driver control position, performance feel and responsiveness, transaxle operation, powertrain noise, ease of starting, idle noise or roughness, hesitation or sag, shutdown characteristics, and response to full-steering turn. All vehicles were tested under the same driving conditions, and the driver was accompanied by a team member. The Neon class was also tested for the controls, operation, and response of the climate control system with the $A C$ both on and off while the vehicle was running.

The Escort and Neon Classes were tested by the same driver. The University of Wisconsin, Madison, placed highest in the dynamic portion of the event for the Escort Class. The team scored high because its vehicle handled well, which was primarily because the batteries were moved from the back seat to under the passenger area of the car, thereby lowering of the center of gravity. Western Washington scored first in the Neon class because its car had a good feel in terms of overall performance with only the electric motor in use (the ICE did not operate because of the high SOC of the batteries). The driver did note it was difficult to shift this vehicle because the clutch was not used in electric-only mode and the driver had to synchronize the motor speed to the gear ratio. The driver for the Saturn Class said he was impressed with all of the vehicles. CSU, Chico scored highest overall in the dynamic event. The driver said the car was exceptional in all three categories (vehicle, powertrain, and driveability). He did note that the vehicle could be improved in terms of stability and hesitation.

The areas highlighted by the drivers for improvement included:

Power Requirements - Several vehicles were under powered, making them difficult to launch.

Interior Noise - Almost all of the vehicles had high interior noise levels that would be unacceptable to a customer, especially the high-pitched whine associated with the electric motors.

Start-Up Schemes - A majority of the vehicles had complicated start-up schemes.

Steering - Manual steering during parking maneuvers would not be a customer-acceptable configuration. Teams implemented the manual steering to decrease power requirements and reduce weight.

Braking - Brake regeneration can provide great benefits to brake performance feel, but it was unrefined.

The scoring of these vehicles was subjective, and every effort was made to obtain judges who were experienced professional drivers. They acknowledged the engineering challenge a hybrid electric vehicle presents. The judges noted the tradeoffs in vehicle handling and performance that must be considered when the weight is increased and two powertrains or sources of power are implemented. They also emphasized the need to concentrate on a vehicle system that is easy to operate, quiet, has adequate acceleration, adequate braking 
performance, and safe handling, qualities that would be found in a production vehicle.

\section{HYBRID DESIGNS}

The hybrid designs were documented through Technical Design Reports, the Engineering Design Review, and special awards. This section discusses successful hybrid vehicles in terms of their performance, reliability, or ingenuity. The intent is not to determine that one approach is better than another, but to examine each approach for its strengths.

The team from Pennsylvania State University (Penn State), a third-year Escort Class team, received the Best Application of Advanced Technology award for its approach to monitoring the charging of the advanced lead-acid batteries. Penn State used Electro Source Horizon batteries to help power its series, charge-sustaining, large electric-only range, hybrid vehicle [4]. Although there was not a problem with the Horizon battery itself, trying to charge 12 of them wired in series did present a problem. These batteries are high-energy-density batteries that have strict charging requirements. The charging cycle recommended by the manufacturer involves a minimum amount of current-limited charging, followed by a voltagelimited charging cycle. The Penn State team was developing a charger to charge the batteries in parallel, but they were unable to complete the charger for the competition, so the team reverted to charging the batteries in series. The team was well aware of the sensitivity of charging these batteries, so within the first two days of the competition, the team developed a 12-channel device that monitored the voltage across each battery which would protect the batteries from overcharging. Each channel was tied into a circuit that was independently powered from the other. A channel monitored the voltage across the battery and compared it with an independent reference voltage. If the battery voltage was greater than the reference voltage, then the extra energy would be diverted to a small lamp. Through this process, the team could determine when the batteries were fully charged. Although the team admits this is not a highly efficient method for charging the batteries, it was considerably less expensive than the only charger recommended for this battery, of which Penn State would have needed four for their system. Penn State's approach, although seemingly simple in concept, was a workable, low-cost solution to a problem with a new advanced technology.

The University of Wisconsin, an Escort Class competitor, was a strong contender in all events and was one of the few reliable series configurations throughout the entire competition. The vehicle was recognized in the design-based events for battery pack design and location, the passive control system (PCS), and the data-logging system.

The location of the battery box was new for 1995. The previous configuration consisted of a single tunnel box through the middle of the vehicle. This design left the vehicle's center of gravity high and resulted in poor handling. In the new design, the battery box was moved to the floor pan below the passenger seats. This design slightly elevated the floor and returned the wagon trunk to its original carrying capacity and even improved the vehicle's handling characteristics. In the Dynamic Event, this team's vehicle had the fastest handling time (100.56 seconds) of any vehicle except the stock neon (100.00 s), which was driven by a professional driver.

The Wisconsin vehicle was an on-road laboratory for the team. The data-logging system, developed by the team, monitored the regenerative brake feel, drive tuning, energy data, and engine power control. A user-friendly display included the vital information collected by the system.

Hybrid passive-control systems are inherently complicated when two sources of power are combined to drive a vehicle. Optimization of a passive control system requires developing a system that monitors each component and implements an operating strategy to run the vehicle at the desired performance level. The team must first determine the objective of the vehicle. Will this vehicle demonstrate high speed, torque, long range, low emissions, high fuel economy, or a combination of these features? The University of Wisconsin team wanted a vehicle that had ultra-low emissions, was easy to use, acceptable to the consumer, and energy-efficient. Wisconsin's vehicle was driven by the electric drivetrain, which drew its power from the lead acid battery pack and a gasoline-powered alternator. Optimization of this series design involved modifying the operation of the vehicle's engine because this was the most inefficient component of the system. The engine had to be optimized to maximize efficiency and minimize emissions. To implement this strategy, the passive control system (PCS) determined when the engine started, idled, increased/decreased power requirements, and shut down on the basis of inputs from the voltage of the battery pack. The PCS had built in strategies for handling unsafe conditions that may arise with the operation of this vehicle. Before it continued implementing changes in vehicle operation, the PCS did the following:

1. Determining if the battery was connected;

2. Made sure the key switch was in the "on" position before the engine started (preventing the car from starting while not being driven); and

3. Determined if the engine was out of fuel to reduce potential damage to the batteries and starter electrical system if the engine was continuously cranked;

4. Determined if the engine was running, which is necessary for switching from hybrid mode to engine-only mode [5].

The University of Tennessee in the Neon Class won top honors. In the Emissions Event, the performance of Tennessee's vehicle led to the first-place finish. The team was also recognized for the level of detail in which it converted the gasoline-powered engine to natural gas with the receipt of the Best Use of Alternative Fuels award.

The team rebuilt the Geo 1.0-L 3-cylinder, 4-stroke engine. The compression ratio in the cylinders was increased from 
9.2:1 to $9.9: 1$ and timing adjustments were made. Siemens Automotive donated prototype $\mathrm{CNG}$ fuel injectors, which were installed in the cylinder head, converting the engine to port injection. An Electromotive TEC 2 engine controller was incorporated into the design because it was easy to mount on the engine for dyno testing and because of the team's previous experience with the system. The Electromotive TEC 2 also has a programmable general-purpose output, which aids in controlling EGR. The vehicle showed the team's attention to detail; for example, the team retained the function of the fuel door for the quick-connect fuel fill, the high-pressure gauge, and the manual shut-off. An EDO composite natural gas fuel tank was used to reduce weight.

This hybrid strategy involved initiating the electric motor when the engine surpassed a threshold absolute manifold air pressure (MAP). At that point, the amount of electric assist was proportional to the MAP. Recharging takes place below a threshold MAP if the SOC reading indicates charging is needed. These thresholds vary for the assist or charging modes, depending on the vehicle's operating conditions. Aside from the technology incorporated into the CNG conversion, the team extensively tested the engine to maximize overall performance. This parallel, electric-assist hybrid obtained ULEV emissions during testing, although fuel economy on the dynamometer rolls was poor [6].

Western Washington University (WWU), a Neon hybrid, placed third in the Neon Class. This vehicle was one of the few vehicles that performed reliably from one event to the next. The team designed the vehicle with the intent that it would achieve ULEV emission levels, demonstrate high fuel economy, acceptable to the consumer, have transparent $\mathrm{HEV}$ operation, and maintain comparable performance characteristics. The team placed first in the Range Event and Consumer Acceptability and second in the Acceleration Event.

The WWU vehicle was a parallel engine-assist hybrid with a small electric range $(5.5 \mathrm{kWh}$ battery capacity @ C/20 discharge rate). The passive control strategy was developed to initiate IC engine operation for its power and range under three specific conditions: the battery pack SOC drops below a predetermined limit, the load on the electric motor exceeds a preset limit for more than $30 \mathrm{~s}$, or the vehicle's speed exceeds $48 \mathrm{~km} / \mathrm{h}$ for more than $30 \mathrm{~s}$ [7].

California State University, Chico was part of the Saturn Class. This team's goal was to design a vehicle with improved fuel economy, reduced emissions, and comfort and performance that match those of today's production vehicles. This series hybrid was driven by AC Propulsion's $150-\mathrm{kW}$ electric motor/controller and was powered by nickel metal hydride batteries and an ethanol-fueled Kohler engine. Chico's control strategy used an off/on approach that was based on the SOC of the battery pack. The vehicle runs on electric power until the SOC drops to $40 \%$. At that point, the generator is engaged and runs until the battery pack returns to $80 \% \mathrm{SOC}$.

The high-efficiency components and the vehicle configuration were selected to increase fuel economy. In the Fuel Economy Event, Chico had the highest hybrid fuel economy at 13.8 $\mathrm{km} / \mathrm{L}$ (SOC-corrected, gasoline equivalent). ETS had a higher fuel economy, but this parallel hybrid was operating in engine-only mode because no four-wheel dynos were available for testing. The Chico team wanted to demonstrate the vehicle's good performance in addition to higher fuel economy. The $150-\mathrm{kW}$ motor provided the power to give Chico's vehicle the fastest acceleration time (10.34 s) of any Challenge vehicle while in electric-only mode [8].

California State University, Fresno was the top overall performer in the Saturn Class. The vehicle performed well in the Emissions and Range Events; as a result, the team took top honors. Reliability of the vehicle was essential to its good performance. Although this team experienced problems with the passive control strategy (see EMISSIONS), there were no component or mechanical system breakdowns. The team used off-the-shelf components and attempted a load-leveling passive-control strategy. CSU, Fresno had a Suzuki 1.3-L, 4cylinder, DOHC, 16-valve engine modified to run on ethanol (E95). The electrical side consisted of a Unique Mobility DC brushless motor and controller powered by Exide lead acid batteries [3].

\section{SUMMARY}

The results from the $1995 \mathrm{HEV}$ Challenge document the performance of 29 student-built, prototype HEV designs. The week-long competition was designed to test a large number of vehicles under similar conditions to find the overall bestperforming vehicle in each of the three classes and to gain insights into the technical potential of HEVs (see Attachment D for complete HEV Challenge Scoring Summary). The individual classes were developed to focus on a particular hybrid type or specific fuels or components (HVAC systems, CNG, or alcohol fuels).

Given the limited time and resources available to the teams of student engineers and the difficulty of the task they faced, the teams built vehicles that performed well. Although a long way from production, the prototypes showed the potential of HEVs to be energy-efficient future vehicles and yet perform like present production vehicles. The ability to capture braking energy is particularly important for improving the efficiency of future $\mathrm{HEV}$ designs, and virtually every school employed this technology.

As in past HEV Challenges, the schools were hampered by the lack of a well-developed heat engine in a size appropriate to their applications, and the difficulty in control system design. The challenge to design a control system that is sufficiently sophisticated to maximize the advantages of the hybrid drivetrain and yet minimize the losses in efficiency that can occur in these complex systems is formidable for 
professionals, let alone undergraduate engineering students. Although also constrained by available energy-storage technologies and the limitations of existing vehicle platforms, the schools fielded the best-performing and most reliable HEVs in the competition's history.

The three HEV Challenges represented the most ambitious and difficult engineering research competitions to date. Although they showed that HEV technology is still developing, these competitions set performance benchmarks and established testing procedures that will affect the engineering community far after the last event was completed.

\section{ACKNOWLEDGMENT}

The work for this paper was supported by the U.S. Department of Energy, Assistant Secretary for Energy Efficiency and Renewable Energy, under contract W-31-109ENG-380.

We want to take this opportunity to recognize and to thank our colleagues at the National Renewable Energy Laboratory and the Idaho National Engineering Laboratory. Also, special thanks go out to the sponsors of the 1995 HEV Challenge.

\section{REFERENCES}

1. W. Salt, M. Duoba, N. LeBlanc "1995 Hybrid Electric Vehicle Challenge Rules and Regulations," Golden, CO, December 1994.

2. R. Kennard, "Engineering Statistics and Quality Control," Marks' Standard Handbook for Mechanical Engineers, 9 Edition., McGraw-Hill: New York, NY, 1986.

3. G. Stevens and R. Moore, "Project Titan--Hybrid Electrical Vehicle Development,” Fresno, CA, May 1995.

4. J. Anstrom, J.H. Fry, D. Ellis, R. Mizikar, "The Pennsylvania State University 1995 Hybrid Electric Vehicle," State College, PA, May 1995.

5. C. Hochgraf, A. Hill, H. Wiegmani, "Refinements to a low-emission series hybrid vehicle," Madison, WI, May 1995.

6. J.W. Hodgson, D. Birdwell, B. Bohannon, L. Bowers, T. DaCunha, W. Dickson, B. Green, B. Fraser, M. Hardin, Y. Isoda, "University of Tennessee 1995 Hybrid Electric Vehicle Design," Knoxville, TN, May 1995.

7. R. Riels and E. West, "Western Washington University 1995 HEV Challenge Vehicle," Bellingham, WA, May 1995.

8. C. Christianson, E. Harrison, J. Moore, S. Brennan, "LAKI, California State University, Chico Hybrid Electric Vehicle," Chico, CA, May 1995. 
Table 7. 1995 HEV Challenge Vehicle Specification Summary

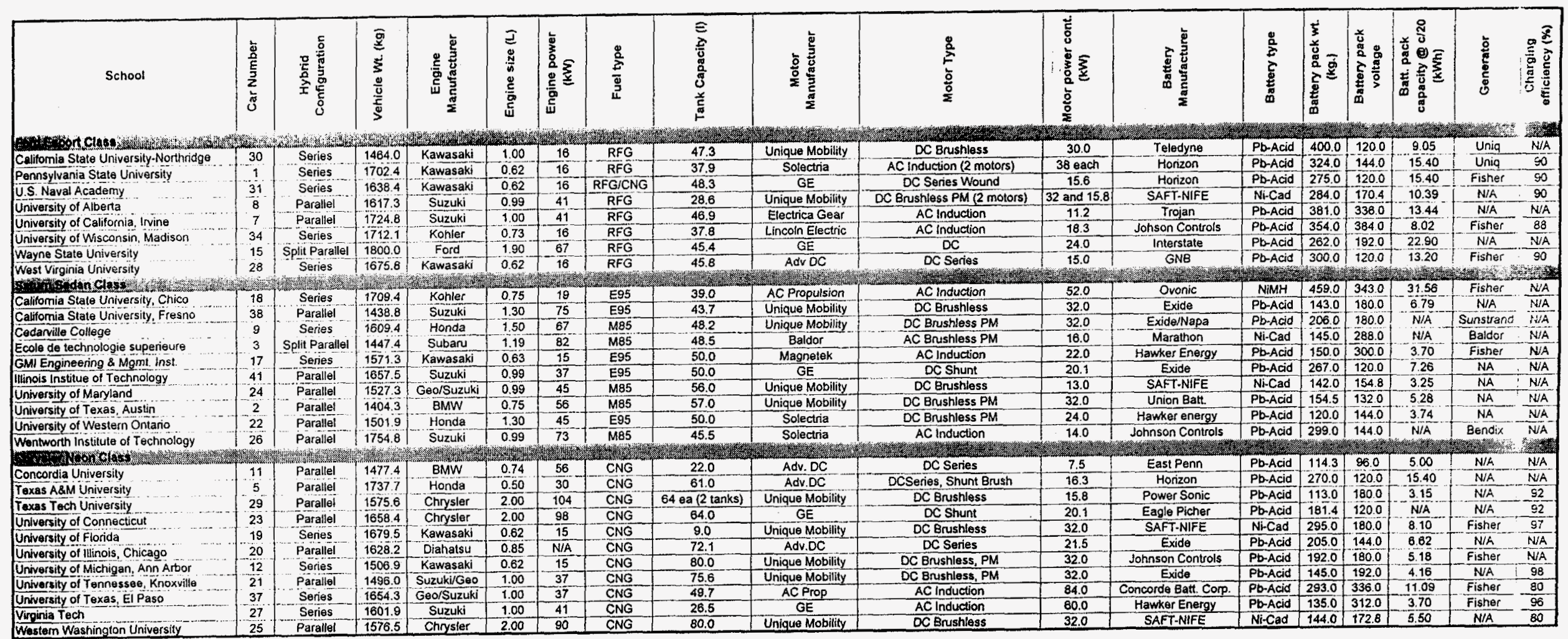




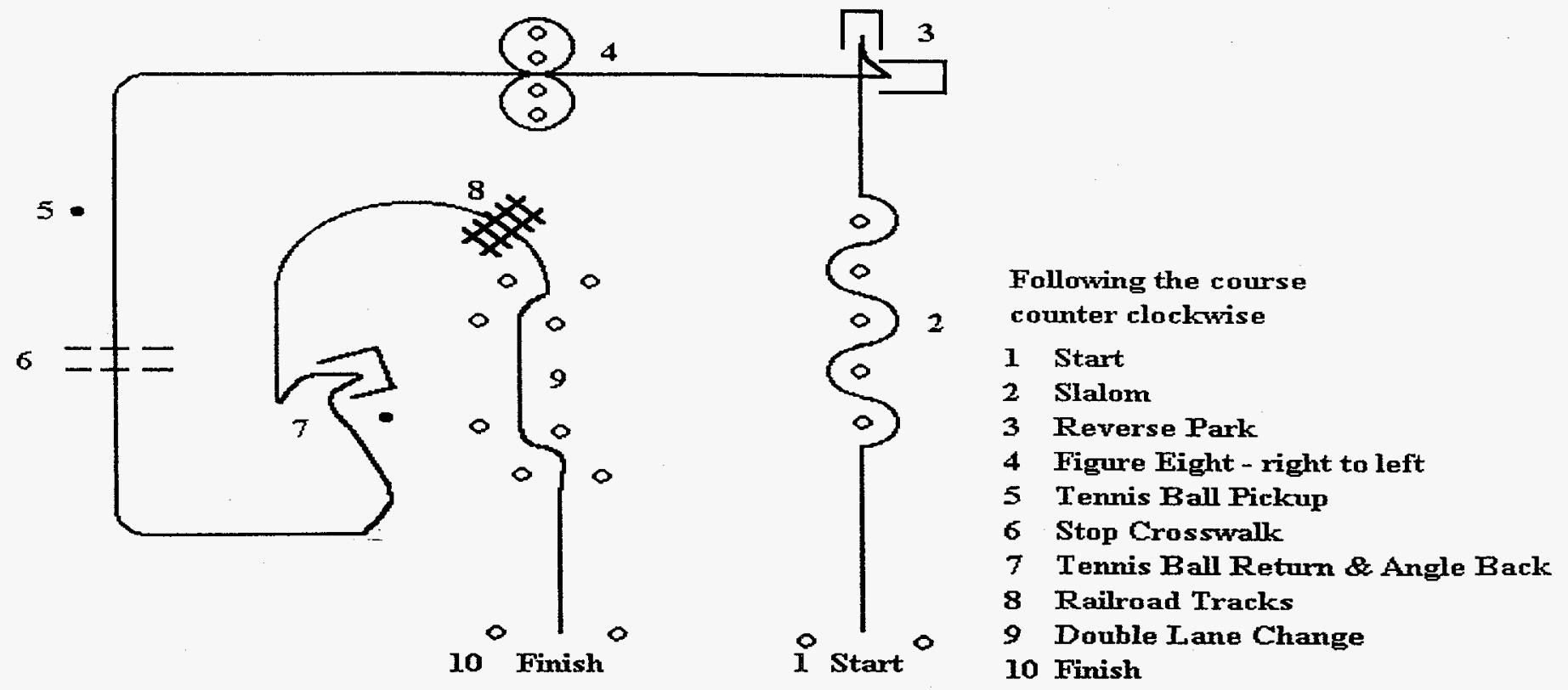

Figure 5. Diagram of a Proposed Handling Course

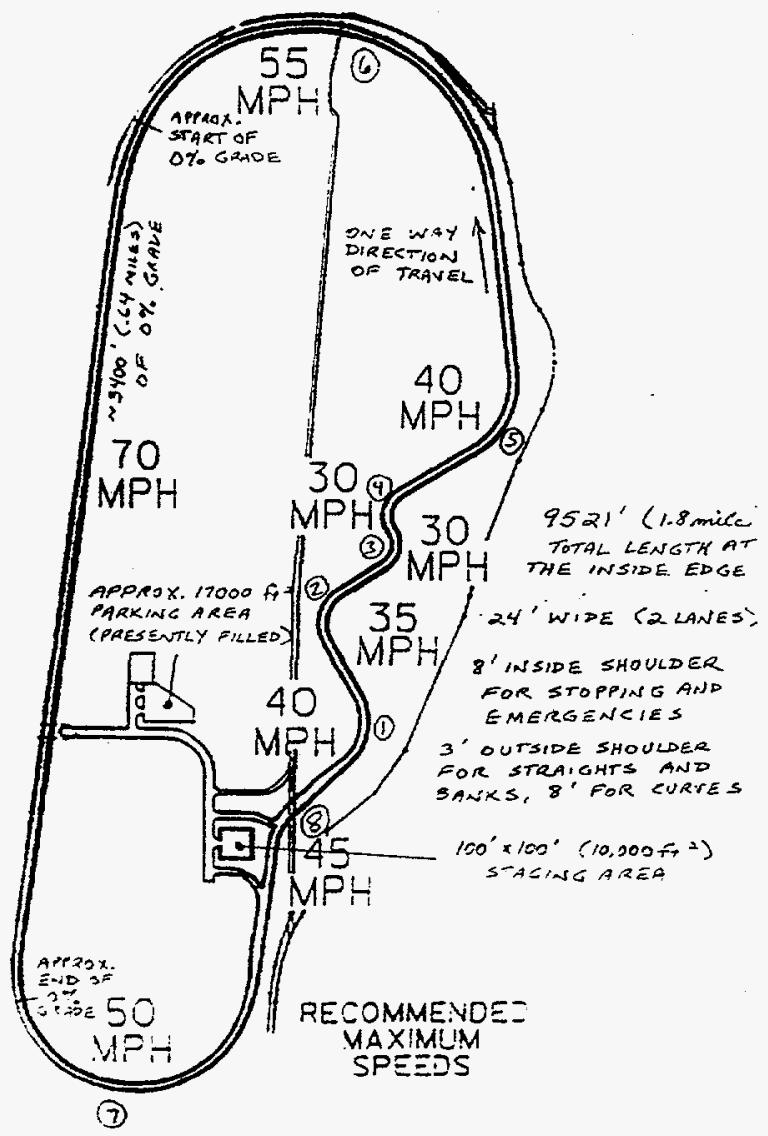

Figure 6. Chrysler Tech. Center's Vehicle Evaluation Road 


\section{$1995 \mathrm{HEV}$ Challenge \\ Consumer Acceptability Event - Dynamic \\ Neon Class}

School

Judge

Vehicle \#

\section{Vehicle Ride/Drive Evaluation}

Vehicle

Handling

Directional Stability

Manuevering/Parking.

Brake Feel/Effectiveness

Road Noise

Driver Control Position

$$
\begin{array}{ccccccccc}
\text { <- poor } & \multicolumn{1}{c}{} & \multicolumn{4}{c}{\text { excellent--> }} \\
1 & - & 2 & - & 3 & - & 4 & - & 5 \\
1 & - & 2 & - & 3 & - & 4 & - & 5 \\
1 & - & 2 & - & 3 & - & 4 & - & 5 \\
1 & - & 2 & - & 3 & - & 4 & - & 5 \\
1 & - & 2 & - & 3 & - & 4 & - & 5 \\
1 & - & 2 & - & 3 & - & 4 & - & 5
\end{array}
$$

Powertrain

Performance Feel, Responsiveness

$$
\begin{aligned}
& <- \text { poor excellent--> } \\
& 1-2-3-4-5 \\
& 1-2-3-4-5 \\
& 1-2-3-4-5
\end{aligned}
$$

Transaxle Operation

Powertrain Noise

Driveability

$$
\begin{array}{ccccccccc}
<- \text { poor } & & & \multicolumn{1}{c}{\text { excellent--> }} \\
1 & - & 2 & - & 3 & - & 4 & - & 5 \\
1 & - & 2 & - & 3 & - & 4 & - & 5 \\
1 & - & 2 & - & 3 & - & 4 & - & 5 \\
1 & - & 2 & - & 3 & - & 4 & - & 5 \\
1 & - & 2 & - & 3 & - & 4 & - & 5 \\
1 & - & 2 & - & 3 & - & 4 & - & 5
\end{array}
$$

Ease of Starting

Idle Noise, Roughness

No Hesitation/Sag

Shut Down Characteristics

Response to Full Steering Turn

Response to AC On/Off, where applicable

$1-2-3-4-5$

BONUS POINTS (Judge's discretionary points)

$\begin{array}{lllllllllllll}0 & 1 & 2 & 3 & 4 & 5 & 6 & 7 & 8 & 9 & 10 & 11 & 12\end{array}$

Total Points 187

Please provide any scoring comments below: 
Table 7. 1995 HEV Challenge Summary of Final Scores

\begin{tabular}{|c|c|c|c|c|c|c|c|c|c|c|c|c|}
\hline Schoul Name & Car & $\begin{array}{l}\text { IIVAC } \\
\text { Event }\end{array}$ & $\begin{array}{l}\text { Acceleration } \\
\text { Event }\end{array}$ & $\begin{array}{c}\text { Cons. Accp. } \\
\text { Event }\end{array}$ & $\begin{array}{c}\text { Emissions } \\
\text { Event }\end{array}$ & $\begin{array}{l}\text { Eng. Design } \\
\text { Review }\end{array}$ & $\begin{array}{l}\text { Range } \\
\text { Events }\end{array}$ & $\begin{array}{c}\text { Dynamic } \\
\text { Performance } \\
\end{array}$ & $\begin{array}{c}\text { Economy } \\
\text { Event }\end{array}$ & $\begin{array}{c}\text { Technical } \\
\text { Report } \\
\end{array}$ & $\begin{array}{l}\text { Total } \\
\text { Sicare }\end{array}$ & Place \\
\hline Availialle l'anuts & & 200 & 100 & 100 & 200 & 100 & 150 & 100 & 150 & 100 & & \\
\hline \multicolumn{13}{|l|}{ Furd listors c llass } \\
\hline Hemeasity of Allucla: & 8 & Whom & 97.7 & 61.5 & 137.1 & 76.9 & 150.0 & 83.4 & 145.2 & 90.1 & 848.0 & 1 \\
\hline 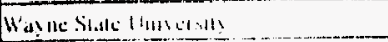 & 15 & 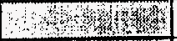 & 78.3 & 28.6 & 200.0 & 20.0 & 120.4 & 89.2 & 150.0 & 77.0 & 703.5 & 2 \\
\hline 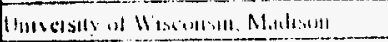 & 14 & $5 \mathrm{~s}, \mathrm{k}$, & 71.7 & 100.0 & 45,7 & 100.0 & 109.5 & 100.0 & 120.0 & 100,0 & 746.9 & 3 \\
\hline West Virginia (Amucusity & 28 & 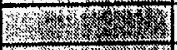 & 58.3 & 26.5 & 85.7 & 59.3 & 30.0 & 79.6 & 120.1 & 61.3 & 520.8 & 4 \\
\hline Unitced Stalc: Nathal Acastemy & .31 & (6y) & 75.8 & 44.6 & 45.7 & 61.6 & 39.4 & 72.9 & 1113 & 59.5 & 510.7 & 5 \\
\hline Penusyh antia Sitc lluivensily & 1 & 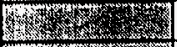 & 70.2 & 35.1 & 40.0 & 91.4 & 36.2 & 82.9 & 30.0 & 75.2 & 461.2 & 6 \\
\hline Univessily of (allifundia, levife & 7 & (8) & 20.0 & 20.0 & 40.0 & 30.4 & 131.3 & 20.0 & 141.8 & 27.9 & 431.4 & 7 \\
\hline Califomia Stalte lluiversity, Nontluidge & 30) & 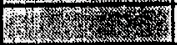 & 0.0 & 0.0 & 0.0 & 29.9 & 0.0 & 0.0 & 0.0 & 20.0 & 49.9 & 8 \\
\hline Colorado Schout of Mines & 10 & 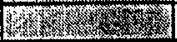 & 0.0 & 0.0 & 0.0 & 0.0 & 0.0 & 0.0 & 0.0 & 43.3 & 43.3 & 9 \\
\hline
\end{tabular}

orado School of Mances

\begin{tabular}{|c|c|c|c|c|c|c|c|c|c|c|c|c|}
\hline Neun Cluss & & & & & & & & & & & & \\
\hline Univensify of lemuessec & 21 & 86.6 & 85.3 & 82.5 & 200.0 & 100.0 & 111.2 & 87.6 & 115.2 & 100.0 & 968.4 & 1 \\
\hline Iexas Jecll Uhivessily & i) & 80.0 & 100.0 & 91.6 & 100.0 & 70.6 & 142.9 & 100.0 & 150.0 & 66.8 & 901.9 & 2 \\
\hline Westcin Waslimg:ten Universty & 25 & 182.4 & 99.3 & 100.0 & 52.0 & 76.9 & 150.0 & 74.4 & 30.0 & 68.4 & 8333 & 3 \\
\hline University ofllowidia & 19) & 135.1 & 76.4 & 76.7 & 0.0 & 61.0 & 0.0 & 78.2 & 0.0 & 68.1 & 495.5 & 4 \\
\hline Virginia Polylecluic Institule & 27 & 89.1 & 90.1 & 70.8 & 0.0 & 83.6 & 0.0 & 47.0 & 0.0 & 97.6 & 478.3 & 5 \\
\hline University of Micligath, Aun Anbor & 12 & 176.5 & 20.0 & 21.2 & 0.0 & 77.3 & 30.0 & 0.0 & 0.0 & 94.2 & 419.3 & 6 \\
\hline Unives sity of Illimesis, (hiciatun & 20 & 0.0 & 84.4 & 74.4 & 0.0 & 33.0 & 42.4 & 0.0 & 0.0 & 83.7 & 317.8 & 7 \\
\hline Lexas AdeM llawiolsily & 5 & 0.0 & 85.3 & 59.5 & 0.0 & 29.2 & 49.4 & 54.7 & 0.0 & 20.0 & 298.1 & 8 \\
\hline University of Comecticul & 23 & 0.0 & 44.1 & 76.5 & 0.0 & 20.0 & 0.0 & 20.0 & 0.0 & 52.6 & 213.2 & 9 \\
\hline Concordial Unincisity & 11 & 0.0 & 0.0 & 20.0 & 0.0 & 74.9 & 0.0 & 0.0 & 0.0 & 84.5 & 179.4 & 10 \\
\hline Universily of lexas, 1. P Pasu & 37 & 0.0 & 0.0 & 0.0 & 0.0 & 38.8 & 0.0 & 0.0 & 0.0 & 58.7 & 97.5 & 11 \\
\hline
\end{tabular}

\begin{tabular}{|c|c|c|c|c|c|c|c|c|c|c|c|c|}
\hline Sarurn Class & & & & & & & & & & & & \\
\hline 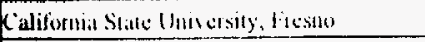 & 38 & 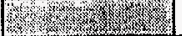 & 92.1 & 97.1 & 200.0 & 65.5 & 150.0 & 100.0 & 91.8 & 55.2 & 851.7 & 1 \\
\hline Ecolc de leclumolengic Sippesticule & 3 & 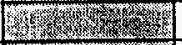 & 97.7 & 100.0 & 98.2 & 77.6 & 30.0 & 87.0 & 150.0 & 88.7 & 729.2 & 2 \\
\hline Califunias Stale Univessity, Chico & 18 & Wing - in & 95.0 & 96.9 & 69.1 & 68.3 & 112.1 & 93.1 & 110.8 & 70.6 & 715.9 & 2 \\
\hline Unisensity of Wescin (Bntutio & 22 & 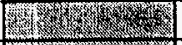 & 20.0 & 91.4 & 40.0 & 87.3 & 130.5 & 20.0 & 30.0 & 76.6 & 195.9 & 4 \\
\hline Univessicy of lexas, Austiu & 2 & 78 & 60.9 & 30.1 & 40.0 & 100.0 & 0.0 & 0.0 & 108.9 & 100.0 & $\$ 399$ & $j$ \\
\hline GM1 Engunecim! \& Mandy cincul fustitute & 17 & 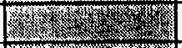 & 71.0 & 73.8 & 40.0 & 24.6 & 43.5 & 83.5 & 68.1 & 34.5 & +39.0 & 0 \\
\hline Illinuis lustitule of Todumolong & 41 & 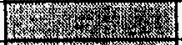 & 80.6 & 20.0 & 200.0 & 20.0 & 0.0 & 20.5 & 51.4 & 30.2 & 4227 & 7 \\
\hline 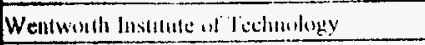 & 26 & Prox & 71.0 & 79.6 & 0.0 & 34.4 & 46.7 & $81: 0$ & 0.0 & 55.8 & 368.5 & 8 \\
\hline University of Marylant & 24 & 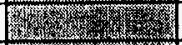 & 0.0 & 29.9 & 0.0 & 75.3 & 0.0 & 0.0 & 0.0 & 84.8 & 189.9 & 9 \\
\hline Cedarville cillligi & 9 & Hery & 0.0 & 24.0 & 0.0 & 58.6 & 0.0 & 0.0 & 0.0 & 78.2 & 160.7 & 10 \\
\hline Alfied University & 36 & 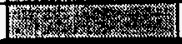 & 0.0 & 0.0 & 0.0 & 0.0 & 0.0 & 0.0 & 0.0 & 20.0 & 20.0 & 11 \\
\hline
\end{tabular}

